\title{
Balancing multiple ecosystem services in conservation priority setting
}

\author{
Liwei Zhang $\cdot$ Bojie Fu $\cdot$ Yihe Lü $\cdot$ Yuan Zeng
}

Received: 27 March 2014 / Accepted: 9 October 2014/Published online: 22 October 2014

(C) Springer Science+Business Media Dordrecht 2014

\begin{abstract}
Conservation priority setting is the critical process of allocating the limited resources available for nature conservation and; safeguarding the sustainability of biodiversity and ecosystem services (ESs). It is difficult, however, to achieve the goal of simultaneously conserving both biodiversity and ESs, not only because of the potential trade-offs between biodiversity and ESs, but also because of the trade-offs between multiple ESs. Thus far, research has focused on the trade-offs between ESs caused by spatial competition resulting from land use change or by the destruction of biophysical interaction between multiple ESs. Few studies, however, have paid attention to the trade-offs induced during the decision-making process. Approaches for measuring the trade-offs between multiple ESs in decision-making processes would thus prove to be extremely helpful. In this paper, we map the water supply, soil conservation, and net primary production as ESs in the Jiangxi province of China in the year 2010, and use risk, tradeoff, and spatial
\end{abstract}

L. Zhang · B. Fu ( $₫) \cdot$ Y. Lü

State Key Laboratory of Urban and Regional Ecology, Research Center for Eco-Environmental Sciences, Chinese Academy of Sciences, Beijing 100085, China e-mail: bfu@rcees.ac.cn

L. Zhang

e-mail: z-lw@foxmail.com

Y. Zeng

Institute of Remote Sensing and Digital Earth, Chinese Academy of Sciences, Beijing 100094, China efficiency indices to measure the conservation efficiency of seven established ordered weighted averaging (OWA) scenarios under two conservation levels (conserving the top ESs at 10 or $20 \%$ of the area of the Jiangxi province). The main results are as follows: (1) conserving one ES may result in inefficient conservation of other ESs; and (2) conserving multiple ESs and the use of GIS-based OWA methods can balance conflicts among multiple ESs and can significantly enhance the spatial efficiency of the identified priority areas. Decision-makers may combine the spatial efficiency, risk and tradeoff levels of each OWA scenario with other specific conservation demands of their own specific cases in order to achieve the optimal identification of priority areas for the simultaneous conservation of multiple ESs.

Keywords Ecosystem services mapping · Biological conservation · Trade-offs · Ordered weighted averaging $\cdot$ Jiangxi province of China

\section{Introduction}

Increasing human activities and the resulting changes to the natural environment are bringing many species to the brink of extinction, with extinction rates of up to 1,000 times higher than pre-human levels being observed and future extinction rates poised to increase (Pimm et al. 1995, 2014). Concomitantly, human wellbeing is declining with the loss of biodiversity (Daily 
1997; Brooks et al. 2006; Jax et al. 2013). Declining biodiversity not only has direct negative effects on human welfare but also results in economic losses (MA 2005). Traditionally, conservationists have focused on conserving biodiversity, mainly through habitat protection, evaluation of endemic or endangered species distribution, and assessment of threats to survival (Brooks et al. 2006; Paviolo et al. 2009). Although biodiversity-focused conservation efforts have had a measure of success in conserving species and habitats (Rodrigues 2006; Wilcove 2008), the sustained high rate of habitat degradation and species loss reveals deficiencies in this approach (Pimm et al. 1995, 2014; Wilcove et al. 1998; MA 2005; Butchart et al. 2010). An alternative approach is to emphasize ecosystem services (ESs), thereby focusing on both the conservation of biodiversity and the sustainable provision of ESs to support human well-being (MA 2005; Tallis et al. 2009). Recently, conservationists have begun integrating the concept of ESs in conservation planning (Balvanera et al. 2001; Egoh et al. 2007; Goldman and Tallis 2009; Polasky et al. 2012) with the goal of identifying priority areas to conserve both biodiversity and ESs. Many researchers have indicated that biodiversity hotspots also tend to be sources of important ESs (Singh 2002; Izquierdo and Clark 2012; Mace et al. 2012). Fisher et al. (2011) suggested that species-led management for the benefit of biodiversity in cultural landscapes could play an important role in the broader delivery of ESs. Meanwhile, according to Chan et al. (2011), incorporating ESs into conservation planning might be most cost-effective when the services are viewed in terms of benefits and costs. Polasky et al. (2012) stated that efforts to increase the value of ESs enhance the conservation of biodiversity and vice versa. Consequently, there are numerous opportunities for safeguarding both biodiversity and ESs (Turner et al. 2007). Nonetheless, identifying areas in which to conserve both biodiversity and ESs simultaneously remains challenging, not only because of the trade-offs between them but also because of the trade-offs among multiple ESs.

Ecosystem services trade-offs in policy-making have arisen when the selection of areas in which to maximize the provision of one ES was a consequence of decreased production in another (Bennett et al. 2009; Haase et al. 2012). Policy-makers did not adequately consider the interrelationships among multiple ESs, which either induced space competition among multiple ESs or undermined the causal interrelationship among multiple
ESs (Lautenbach et al. 2010). Recently, researchers have paid more attention to the trade-offs between ESs and human well-being, ESs and economic benefits, ESs and biodiversity, and ESs and land use, among others (Rodríguez et al. 2006; Nelson et al. 2009; Carreño et al. 2012; Maes et al. 2012; Hussain and Tschirhart 2013), with few of them focusing on the trade-offs among multiple ESs in conservation priority setting (Luck et al. 2012; Liu et al. 2013). There is thus an urgent need to study the trade-offs among multiple ESs in decisionmaking processes. One of the multi-criteria evaluation methods, the ordered weighted averaging (OWA) method was first developed in the context of fuzzy set theory (Yager 1988). The use of the OWA method combined with the GIS platform has proved to be an effective approach in balancing multiple conflicting objectives in decision-making processes, and has been used in numerous practical applications to identify priority areas (Jiang and Eastman 2000; Malczewski et al. 2003; Malczewski and Rinner 2005; Robinson et al. 2010; Liu et al. 2013; Ricardo et al. 2013; Amiri et al. 2013).

In this study, we selected the Jiangxi province of China as a typical case analysis area, and: (1) based on the MA classification frameworks of ESs, explicitly mapped the distribution patterns of three ESs spatially-water supply (provisioning ESs), soil conservation (regulating ESs), and net primary production (NPP) of vegetation (supporting ESs) of the Jiangxi province in 2010; (2) analyzed the spatial efficiency of focusing on the conservation of an individual ES or multiple ESs simultaneously in accordance with two levels of conservation targets-protecting the top values of ESs in 10 or $20 \%$ of the Jiangxi province's area; and (3) discussed the application of the GISbased OWA method to balancing multiple ESs in identifying priority areas when conserving multiple ESs. The findings may have significant implications for informing effective conservation of multiple ESs.

\section{Materials and methods}

Study area

The Jiangxi province $\left(113.57 \sim 118.5^{\circ} \mathrm{E}, 24.5 \sim 30.1^{\circ} \mathrm{N}\right)$ is located in the southeastern portion of China with Nanchang as its capital (Fig. 1). Jiangxi has an area of approximately 167 thousand square kilometers and had a population of 45.04 million people in 2012 . The main 
Fig. 1 Location, meteorological stations, and land use/land cover types in the Jiangxi province

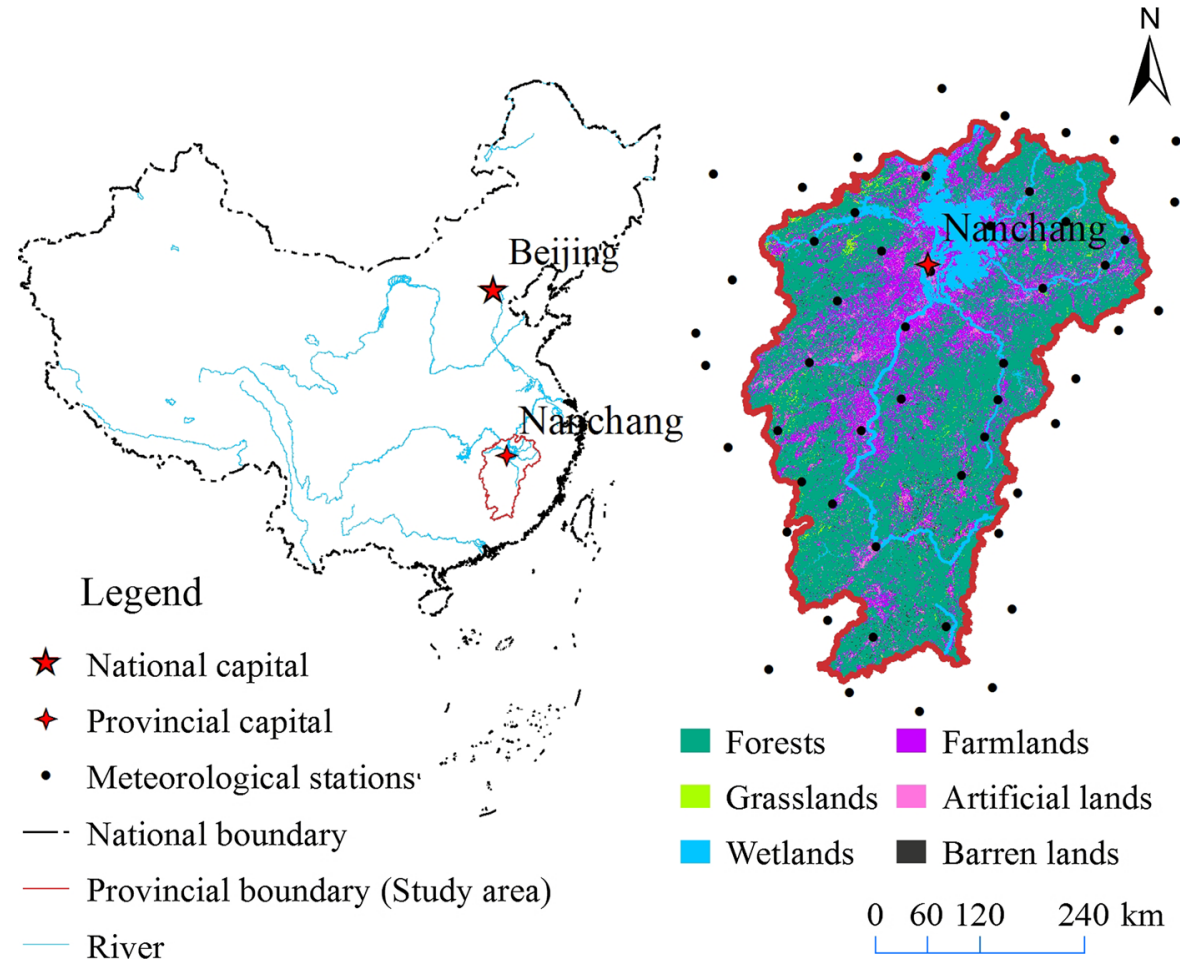

climate type in Jiangxi is a subtropical monsoon climate, and the annual mean air temperature and precipitation amount to approximately $18{ }^{\circ} \mathrm{C}$ and $1,700 \mathrm{~mm}$, respectively. Major soil types include red soil, weakly developed red soil, and brown soil (Ding et al. 2013). The dominant land use type is forests, which account for $66 \%$ of Jiangxi's area, followed by $21 \%$ farmland, $6 \%$ artificial land, $5 \%$ wetland, $2 \%$ grassland, and $1 \%$ barren land (Fig. 1). Poyang Lake is the largest freshwater lake in China; it is located in the northern part of Jiangxi, which is also the home to internationally important freshwater wetlands that serve as habitat for a number of endangered waterfowl species ( $\mathrm{Li}$ et al. 2013). In recent years, conservation of biodiversity and ESs has been of great concern because population growth and economic development have imposed enormous constraints on the natural environment of the Jiangxi province (He et al. 2012).

\section{Mapping ESs}

\section{Water supply}

The water supply (WY) model is based on the Budyko assumption and annual average precipitation (Budyko
1974). Annual actual evapotranspiration (ET) was estimated using the empirical model presented by Zhang et al. (2001):

$W Y=P-E T$

$E T=\frac{P\left(1+\omega \frac{P E T}{P}\right)}{1+\omega \frac{P E T}{P}+\left(\frac{P E T}{P}\right)^{-1}}$

where $P$ refers to the annual total precipitation $(\mathrm{mm})$ and $P E T$ refers to annual potential evapotranspiration (PET), which was calculated via the Hamon method (Hamon 1963; Lu et al. 2005). The $\omega$ parameter is the plant-available water coefficient; it was assigned a value of 2.0 for woodland, 1.0 for shrub-land, 0.5 for grassland and cropland, and 0.1 for artificial land and barren land in this study (Zhang et al. 2001; Lu et al. 2013). The ET of a water body was defined as the minimum of $P$ and $P E T$, i.e., $E T=\operatorname{Min}(P, P E T)(\mathrm{Lu}$ et al. 2013).

\section{Soil conservation}

Annual soil loss can be calculated using the RUSLE empirical model (Wischmeier and Smith 1965) as follows: 
Table 1 Values of $\mathrm{C}$ and $P$ factors in the Jiangxi province (Lu et al. 2011; Yu et al. 2011)

\begin{tabular}{lllll}
\hline Land use types & C values & Land use types & Slope $(\theta) / \%$ & $P$ values \\
\hline Water body & 0 & Agriculture land & $0<\theta \leq 5$ & 0.11 \\
Forestland & 0.003 & & $5<\theta \leq 10$ & 0.12 \\
Residential area & 0.003 & & $10<\theta \leq 20$ & 0.14 \\
Paddy field & 0.088 & & $20<\theta \leq 30$ & 0.19 \\
Grassland & 0.050 & & $30<\theta \leq 50$ & 0.25 \\
Dry-cropland & 0.120 & & $\theta>50$ & 0.33 \\
Bare land & 1 & Forestland & $\theta \geq 0$ & 0.80 \\
Unused land & 1 & Other land & $\theta \geq 0$ & 1.00 \\
\hline
\end{tabular}

$$
\begin{aligned}
& A=R \times K \times L S \times C \times P \\
& R=\sum_{i=1}^{12} 1.735 \times 10^{\left(1.5 \times \lg \frac{p_{i}^{2}}{p_{a}}-0.8188\right)} \\
& K=\left\{0.2+0.3 e^{\left[-0.0256 S_{a}\left(1-\frac{s_{i}}{100}\right)\right]}\right\}\left(\frac{S_{i}}{C_{i}+S_{i}}\right)^{0.3} \\
& \times\left\{1.0-\frac{0.25 C}{\left[C+e^{(3.72+2.95 C}\right]}\right\} \\
& \times\left\{1.0-\frac{0.7\left(1-\frac{s_{a}}{100}\right)}{\left(1-\frac{s_{a}}{100}\right)+e^{\left(-5.51+22.91-\frac{s_{a}}{100}\right.}}\right\} \\
& L=\left(\frac{\lambda}{22.13}\right)^{m}\left\{\begin{array}{rr}
m=0.5 & \theta \geq 9 \\
m=0.4 & 9>\theta \geq 3 \\
m=0.3 & 3>\theta \geq 1 \\
m=0.2 & 1>\theta
\end{array}\right. \\
& S=\left(\frac{\sin \theta}{0.0896}\right)^{0.6}
\end{aligned}
$$

where $A$ is the estimated average soil loss $\left(\mathrm{t} \mathrm{hm}^{-2-}\right.$ year $\left.^{-1}\right) ; R$ is the rainfall erosivity factor calculated by means of the Wischmeier empirical formula (Wischmeier and Smith 1978), $P_{\mathrm{i}}$ is the monthly precipitation $(\mathrm{mm}) ; p_{a}$ is the total annual precipitation ( $\left.\mathrm{mm}\right)$; $K$ is the soil erodibility factor calculated using the EPIC (Erosion-Productivity Impact Calculator) equation (Sharpley and Williams 1990), $s_{a}, s_{i}, s_{l}$, and $c$ are the percentage (\%) of sand, clay, silt, and organic matter in soil, respectively; $L$ is the slope length factor (Wischmeier and Smith 1978); $S$ is the slope steepness factor (Zhou and Liu 2006); $m$ is a dimensionless constant depending on the percent slope $(\theta)$; $C$ is the crop and management factor; and $P$ is the conservation practices factor. Values of the $\mathrm{C}$ and $\mathrm{P}$ factors are presented in Table 1, and are quoted from studies that researched soil erosion in the Jiangxi province ( $\mathrm{Lu}$ et al. 2011; Yu et al. 2011).

If both $C$ and $P$ are assigned a value of 1 , then the calculated soil erosion is the potential soil erosion. Therefore, the level of soil conservation can be estimated based on the difference between potential soil erosion and actual soil erosion. The soil conservation equation is as follows:

$A_{S C}=R \times K \times L S \times(1-C \times P)$,

where $A_{s r}$ refers to the annual amount of soil conserved ( $\mathrm{t} \mathrm{hm}^{-2}$ year $\left.^{-1}\right)$; the other parameters were calculated using Eq. (3).

\section{NPP}

The terrestrial Carnegie Ames-Stanford Approach (CASA) was used to estimate the NPP of ecosystems (Potter et al. 1993). The CASA model advocates calculating the NPP of vegetation as the product of the modulated absorbed photo-synthetically active radiation (APAR) and the light use efficiency $(\varepsilon)$ factor (Potter et al. 1993):

$\operatorname{NPP}(x, t)=\operatorname{APAR}(x, t) \times \varepsilon(x, t)$,

where NPP is the net primary production of location $x$ at time $t$, APAR is the canopy-absorbed incident solar radiation $\left(\mathrm{MJ} \mathrm{m}^{-2}\right)$, and $\varepsilon$ parameter is the light use efficiency $\left(\mathrm{g} \mathrm{C} \mathrm{MJ}^{-1}\right.$ ) of APAR. Data needs for the CASA model include land cover, NDVI, and climate data. The annual total NPP $\left(\mathrm{g} \mathrm{C} \mathrm{m}^{-2}\right.$ year $\left.^{-1}\right)$ is the sum of the NPP for each of the twelve months within a year. All the data used to map water supply, soil conservation and NPP are presented in Table 2. 
Table 2 The datasets used for mapping ecosystem services

\begin{tabular}{lllll}
\hline Datasets & Data type & Spatial resolution & Time scale & Data sources \\
\hline Meteorological data & Point & & 2010 & http://cdc.cma.gov.cn/ \\
Topographical parameters & Raster & $90 \mathrm{~m}$ & 2000 & http://srtm.csi.cgiar.org \\
MODIS NDVI & Raster & $250 \mathrm{~m}$ & 2010 & http://ladsweb.nascom.nasa.gov/data/ \\
Soil properties & Raster & $1 \mathrm{~km}$ & 2009 & http://westdc.westgis.ac.cn \\
Remote-sensing data & Raster & $30 \mathrm{~m}$ & 2010 & http://earthexplorer.usgs.gov/ \\
\hline
\end{tabular}

The daily meteorological data (solar radiation, precipitation and temperature) for 2010 were retrieved from the China Meteorological Data Sharing Service System and 52 stations (Fig. 1) within and around the Jiangxi province were used to produce the interpolation raster maps using ArcGIS 9.3 software via the Kriging method. Topographical parameters were derived from STRM digital elevation data. The 250 m MODIS NDVI data were composites of 16-day NDVI maximum values and were acquired from the Level 1 and Atmosphere Archive and Distribution System. The soil properties data used in the RUSLE model came from the Chinese soil data set (Fischer et al. 2008). The land use type data were interpreted from the Landsat 5 TM in June 2010 based on the classification methods of decision trees in eCognition software (DeFiniens 2004). The accuracy levels of land use type maps were above $94 \%$ and thus meet the accuracy requirements of the ESs mapping models (Wang et al. 2014). All the data were interpolated or resampled into $250 \mathrm{~m}$ resolution prior to being entered as input into the models for further analysis

GIS-based ordering weight averaging (OWA)

For a given set of $\mathrm{n}$ criterion maps, OWA is defined as (Yager 1988; Jiang and Eastman 2000):

$O W A\left(x_{i j}\right)=\sum_{i}^{n} w_{i} s_{i j},\left(w_{i} \in[0,1]\right.$ and

$\sum_{i}^{n} w_{i}=1$, for $i$ and $\left.j=1,2,3, \ldots, n\right)$,

where $x_{i j}$ refers to the criterion maps. In this study, the criterion maps are the three ESs raster maps after normalization. In order to avoid any impacts from differences in data units, the attribution values of the three ESs were normalized to a scale ranging from 1 to 1,000 based on a min-max normalization prior to reordering them as the input data for OWA. Theoretically, the attribution values of the ESs can be normalized into any interval ranges convenient to the specific study. Meanwhile, $s_{i j}$ is the sequence obtained by reordering the attribute values of criterion maps $\left(x_{i j}\right)$ in descending order, $w_{i}$ is the ordered weights of the reordering maps $\left(s_{i j}\right)$, and $n$ is the total number of criterion maps. For example, given a set of attribute values at the $i$-th location on the $j$-th criterion maps, we have $x_{i j}(0.7,0.1,0.9)$ and a set of associated order weights, $w_{i}(0.12,0.11,0.77)$. The OWA calculation process involves: (1) reordering attribute values $x_{i j}$ in descending order as follows: $s_{i j}(0.9,0.7,0.1)$, and (2) combining the weighed ordered attribute values as follows: $\mathrm{OWA}=(0.9 \times 0.12)+(0.7 \times 0.11)+$ $(0.1 \times 0.77)=0.262$.
OWA scenarios based on risk and tradeoff levels

The risk and tradeoff of the various selected order weights can be formulated as follows (Yager 1988; Jiang and Eastman 2000; Malczewski et al. 2003):

$$
\text { risk }=(n-1)^{-1} \sum_{i}^{n}(n-i) w_{i} \quad(0 \leq \text { risk } \leq 1)
$$

$$
\begin{aligned}
& \text { tradeoff }=1-\sqrt{\frac{n \sum_{i}^{n}\left(w_{i}-\frac{1}{n}\right)^{2}}{n-1}} \\
& (0 \leq \text { tradeoff } \leq 1),
\end{aligned}
$$

where $n$ is the total number of criterion maps, and $w_{i}$ is the weight for the $i$ th order. Theoretically, an infinite number of scenarios can be obtained by varying the risk and tradeoff levels within the decision strategy space of OWA. If the decision-makers are inclined to assign high weight value to the low criterion attribute values, they are more likely to obtain low-risk (risk-aversion) values; if they are inclined to assign high weight value to the high criterion attribute values, they will obtain high-risk (risk-taking) values. If the decision-makers assign the same weight values to each criterion attribute value $\left(w_{\mathrm{i}}=1 / n\right)$, they are more likely to get the maximum tradeoff value. If the highest or lowest criterion attribute values with are ascribed a value of 1 , they will get a tradeoff value of 0 (Yager 1988; Jiang and Eastman 2000; Malczewski et al. 2003; Liu et al. 2013). The higher the risk values of the scenarios, the higher the risk of losing ESs, as the criterion attribute value is lowest in a specific location. The higher the tradeoff values of the 
scenarios, the more the information from each ES is weighted in the final OWA results. Different combinations of the risk and tradeoff indices will result in different degrees of spatial trade-off levels.

Given the definitions of risk and tradeoff indices, the set of optimal order weights (scenario) is obtained by solving the nonlinear mathematical programming problem (Malczewski et al. 2003) of three equations: (14), (13), and (11).

maximize tradeoff $=1-\sqrt{\frac{n \sum_{i}^{n}\left(w_{i}-\frac{1}{n}\right)^{2}}{n-1}}$

$(0 \leq$ tradeoff $\leq 1)$

$w_{i} \in[0,1]$ and $\quad \sum_{i}^{n} w_{i}=1$,

for $i$ and $j=1,2,3, \ldots, n$.

where the definitions of the parameters in Eqs. (13) and (14) are the same as in Eqs. (10), (11), and (12). The solution to this problem determines the maximum degree of tradeoff for a given degree of risk levels. In order to explore the conservation efficiency of different sets of weight combinations in the identification of priority areas, we limited our analysis to seven arbitrary scenarios based on the seven established risk levels (Fig. 2).

\section{Conservation efficiency evaluation method}

The conservation efficiency of priority areas for a single ES or multiple ESs can be ascribed a value using the spatial efficiency index (Liu et al. 2013).

$S E=\frac{\frac{E p}{E}}{\frac{S p}{S}}$,

where $S E$ refers to the spatial efficiency index, $E p$ describes the total ES of the identified priority areas, $E$ encompasses the total ES of the whole region, $S p$ is the area of priority areas, and $S$ is the area of the entire region. The identification of an area should be regarded as efficient if its $S E$ is greater than 1 . The value of $S E$ is dimensionless.

\section{Results}

Efficiency of conserving single ES

By mapping the NPP, water supply, and soil conservation, we identified the priority areas for Jiangxi

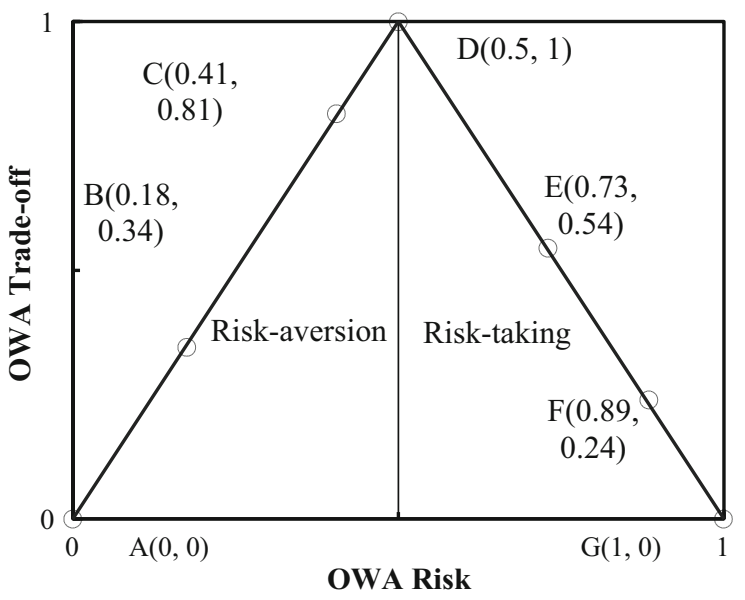

Fig. 2 Distributions of the seven developed scenarios in the risk and tradeoff decision strategy space. The risk and trade-off value of the order weights of each scenario are as follows: A ( 0 , $0), \mathrm{B}(0.18,0.34), \mathrm{C}(0.410 .81), \mathrm{D}(0.5,1), \mathrm{E}(0.73,0.54), \mathrm{F}$ $(0.89,0.24)$, and $G(1,0)$. The order weights of the scenarios, which correspond to each established risk and tradeoff value, of the three criterion maps are as follows: A $[0,0,1], \mathrm{B}[0.12,0.11$, 0.77], C [0.21, 0.39, 0.40], D [0.33, 0.33, 0.33], E [0.49, 0.48, $0.03], \mathrm{F}[0.84,0.09,0.07]$, and $\mathrm{G}[1,0,0]$

based on two levels of conservation targets, namely, protecting areas with the top ES values in 10 or $20 \%$ of the area of the Jiangxi province in the year 2010. The results indicate that the spatial distribution patterns of the water supply priority areas were gathered in the northeastern part of the study area, the NPP priority areas were mainly scattered in the northeastern and southern areas of the study area, and the soil conservation priority areas were mainly scattered in the mid-eastern portion of the study area (Fig. 3). Because the various ecosystems in an area produce and deliver vital goods and services that are also important to human society (Daily 1997; MA 2005; Bennett et al. 2009), the protection of an individual ES will often indirectly protect other types of ESs in the priority areas. After comparing the spatial efficiency of priority areas for a single ES in accordance with two specific conservation levels, the spatial efficiency can be concluded to decrease with the increase in area, and only the selected individual ES has the highest spatial efficiency. In addition, the priority areas of the other ESs in the same locations both have the lowest spatial efficiency (Table 3).

The relationships of trade-offs among multiple ESs can be tested using the Pearson correlation coefficient (Butler et al. 2011). If the Pearson correlation coefficient 

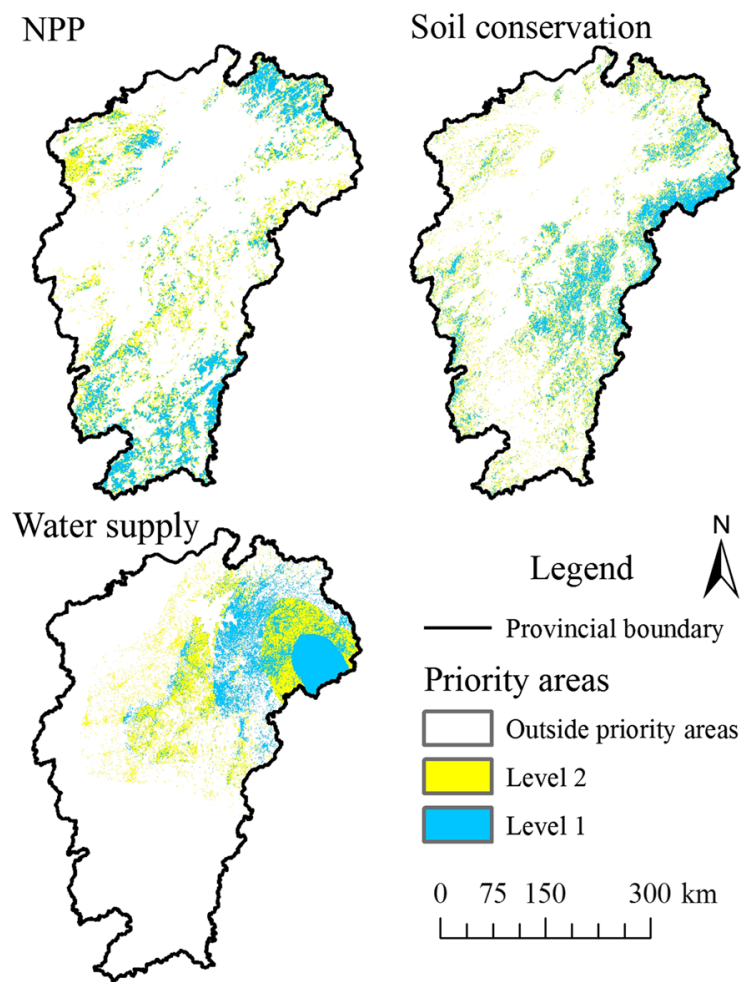

Fig. 3 Priority areas for conserving individual ecosystem services. The area of the level 2 priority areas includes the level 1 priority areas

is positive, a synergic relationship exists between two ESs. If the Pearson correlation coefficient is negative, a trade-off relationship exists between the two ESs. We used the Band Collection Statistics module of ArcGIS software to calculate the Pearson correlation coefficient matrix, which can reveal the relationships in the spatial distribution of three ES raster maps. The results demonstrate that a synergic relationship exists between the spatial distribution of NPP and soil conservation $(r=0.498, p>0.01)$, and a spatial trade-off exists between the water supply and NPP $(r=-0.312$, $p>0.01)$ or water supply and soil conservation $(r=-0.110, p>0.01)$. Thus, if we select the water supply as the target ES for conservation, neither NPP or soil conservation will be efficiently protected at all. Similarly, if we select NPP or soil conservation as the target ES for conservation, the water supply will not be efficiently protected (Table 3 ).

In sum, the identification of priority areas for individual ESs can only achieve a maximum spatial efficiency for themselves, and cannot ensure the highest spatial efficiency in the other ESs
Table 3 Spatial efficiency characteristics of the single ecosystem services for the two conservation target levels

\begin{tabular}{llll}
\hline Ecosystem services (levels) & \multicolumn{3}{l}{ Spatial efficiency } \\
\hline NPP (1) & $1.196^{\mathrm{a}}$ & 0.904 & 1.127 \\
Water supply (1) & 0.809 & $1.428^{\mathrm{a}}$ & 1.041 \\
Soil conservation (1) & 1.316 & 0.963 & $2.693^{\mathrm{a}}$ \\
NPP (2) & $1.181^{\mathrm{a}}$ & 0.922 & 1.125 \\
Water supply (2) & 0.845 & $1.354^{\mathrm{a}}$ & 0.989 \\
Soil conservation (2) & 1.372 & 0.933 & $2.224^{\mathrm{a}}$ \\
\hline
\end{tabular}

a The data marked with in the spatial efficiency column refers to the spatial efficiency of the proactively protected individual ecosystem service. The value of spatial efficiency is dimensionless

simultaneously, especially when spatial trade-off relationship exists among them.

Efficiency of conserving multiple ESs

According to the changes in risk and tradeoff levels under different ordered weights of OWA, seven scenarios (Fig. 3) were developed for analyzing the conservation efficiency of conserving multiple ESs simultaneously. The spatial efficiency index was used to evaluate the conservation efficiency of priority areas in every scenario under two conservation levels. Level 1 aimed at conservation of the top OWA values in $10 \%$ of the area of the study areas, and level 2 sought for conservation of the top OWA values in $20 \%$ of the area of the study areas.

As shown in Table 4, the spatial efficiency of both priority areas decreases from scenarios $B$ to $G$, and the spatial efficiency of scenario A is lower than B but greater than other scenarios with increasing risk levels. With the values of risk increasing from 0 to 0.5 and the trade-offs of every scenario increasing from 0 to 1 (scenarios A, B, C and D), the spatial efficiency of soil conservation decreases, while the spatial efficiency of water supply increases. With the values of risk increasing from 0.5 to 1 and the tradeoff decreasing from 1 to 0 (scenarios $E, F$ and $G$ ), the spatial efficiency of NPP increases, while the spatial efficiency of water supply decreases. Under the conservation target of level 1 , only the spatial efficiency of water supply in scenario $\mathrm{G}$ is lower than 1 . However, under the conservation target of level 2, the spatial efficiency of water supply in scenarios $A$ and $G$ is lower than 1. 
Table 4 Spatial efficiency of the seven scenarios for the two conservation target levels

\begin{tabular}{lllll}
\hline $\begin{array}{l}\text { Scenarios } \\
\text { (levels) }\end{array}$ & NPP & $\begin{array}{l}\text { Water } \\
\text { yield }\end{array}$ & $\begin{array}{l}\text { Soil } \\
\text { retention }\end{array}$ & Average \\
\hline $\mathrm{A}(1)$ & 1.126 & 1.051 & 2.683 & 1.620 \\
$\mathrm{~B}(1)$ & 1.130 & 1.113 & 2.639 & 1.627 \\
$\mathrm{C}(1)$ & 1.121 & 1.282 & 2.182 & 1.528 \\
$\mathrm{D}(1)$ & 1.128 & 1.278 & 2.174 & 1.526 \\
$\mathrm{E}(1)$ & 1.105 & 1.343 & 1.665 & 1.371 \\
$\mathrm{~F}(1)$ & 1.151 & 1.173 & 1.836 & 1.387 \\
$\mathrm{G}(1)$ & 1.170 & 0.869 & 1.268 & 1.102 \\
$\mathrm{~A}(2)$ & 1.125 & 0.992 & 2.226 & 1.448 \\
$\mathrm{~B}(2)$ & 1.127 & 1.058 & 2.179 & 1.455 \\
$\mathrm{C}(2)$ & 1.102 & 1.233 & 1.763 & 1.366 \\
$\mathrm{D}(2)$ & 1.111 & 1.222 & 1.774 & 1.369 \\
$\mathrm{E}(2)$ & 1.085 & 1.282 & 1.383 & 1.250 \\
$\mathrm{~F}(2)$ & 1.151 & 1.069 & 1.670 & 1.297 \\
$\mathrm{G}(2)$ & 1.163 & 0.885 & 1.332 & 1.127 \\
\hline
\end{tabular}

The value of spatial efficiency is dimensionless

With the fixed size of the conservation area, the spatial locations of the identified priority areas vary significantly in location within the study area, as a result of the variations in risk and tradeoff levels caused by the different decision scenarios. Figure 4 shows that with the increase of risk values from scenario A to scenario $G$, the spatial distribution patterns of the selected priority areas under two conservation levels are first scattered in the central eastern section of the study area (scenarios A and B), then concentrated in the northeastern portion of the study area (scenarios C, D, and E), and finally scattered in the northeastern and southern portion of the study area (scenarios $F$ and G).

The characteristics of spatial efficiency in Tables 3 and 4 illustrate that the spatial efficiency decreases with increasing size of the area when using the OWA method to identify conservation priority areas for multiple ESs. Moreover, the priority areas selected by means of the OWA method greatly improved the spatial efficiency of conserving the three ESs simultaneously. However, the spatial efficiency of each ES was lower in the priority areas when the conservation of a single ES was the sole purpose. Therefore, employing the OWA method can balance the tradeoffs between multiple ESs and can significantly enhance the spatial efficiency of the priority areas identified for conserving multiple ESs simultaneously.

\section{Discussion \\ Importance of conserving multiple ESs simultaneously}

The final decisions of the optimal priority areas identified for conservation or rehabilitation must match the demands of conservation targets, which are either determined by a series of biophysical thresholds or meet the subjective purpose of decision-makers or stakeholders (Margules and Pressey 2000; Malczewski et al. 2003; Wilson et al. 2009; Luck et al. 2012; Moilanen et al. 2013). In conserving an individual ES, the processes involved in the identification of priority areas are very simple. If areas with the highest spatial efficiency levels are taken as the selection criterion, the final priority areas selected for conserving a single ES can be identified as shown in Fig. 3. However, in this case, only the single ES had the highest spatial efficiency, and focusing solely on it may induce inefficient conservation of the other ESs (Table 3). In conserving multiple ESs, seven conservation scenarios were developed using different combinations of ordering weights of criterions on ES maps, and the spatial efficiency and the risk and tradeoff levels of each OWA scenario were measured. If relatively low risk and low tradeoff levels are presumed to be the optimal choice in scenarios with the highest levels of spatial efficiency, which may match the demands of final conservation goals, the priority areas determined for scenario B should be the optimal selection (Fig. 4 and Table 4). Generally, the optimal priority area for conservation requires conservation efficiency and, conservation costs and benefits (Margules and Pressey 2000; Wilson et al. 2009; Chan et al. 2011; Luck et al. 2012; Moilanen et al. 2013) to be balanced. Following the procedures outlined in this paper, decision-makers may integrate spatial efficiency and, OWA risk and tradeoff levels with other specific conservation demands, such as the connectivity, costs and benefits, land use, and climate change levels of the priority areas (Moilanen et al. 2013), in order to achieve their final conservation targets and make effective conservation plans. 

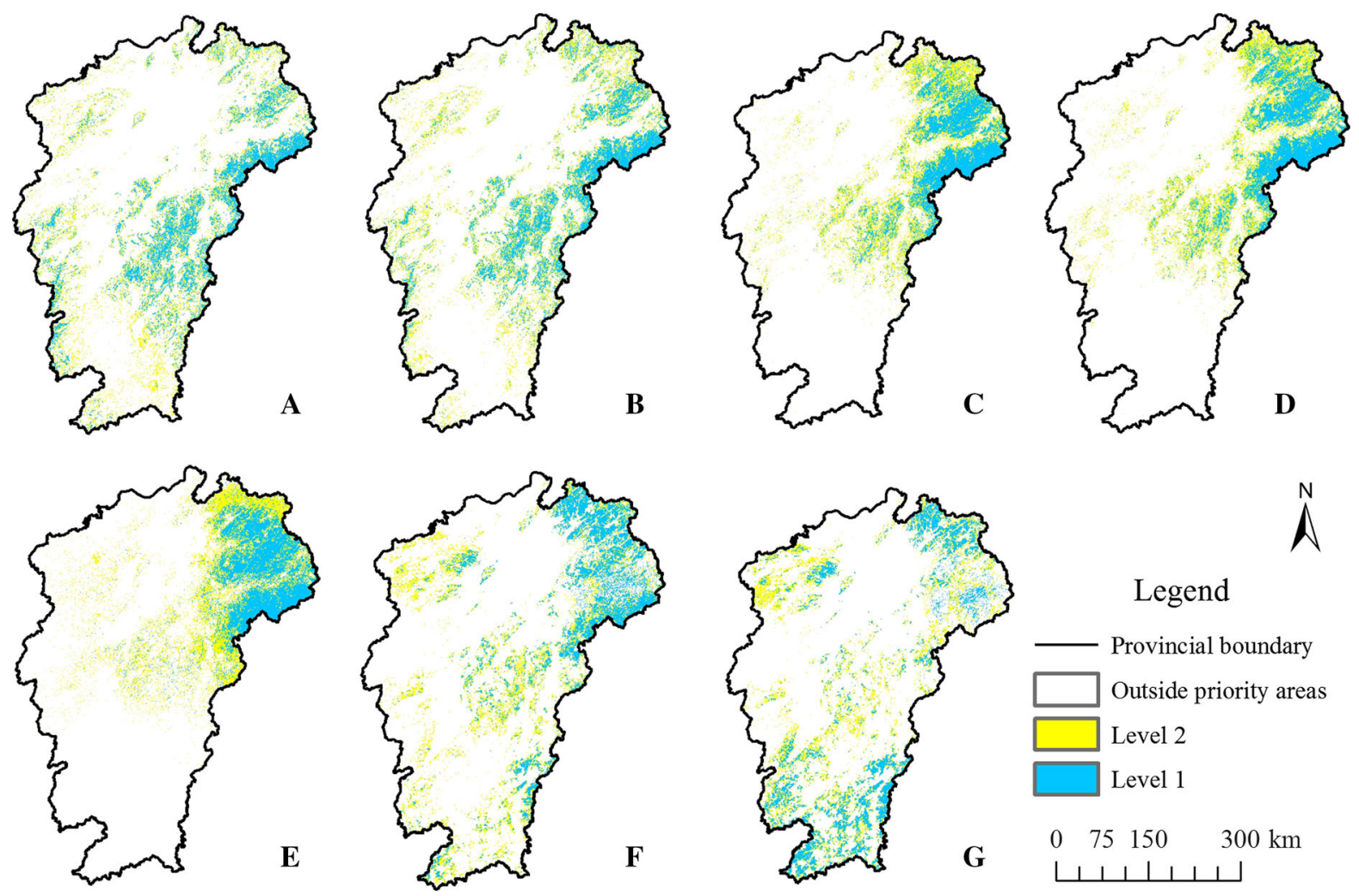

Fig. 4 Priority areas of the seven developed OWA scenarios for conserving multiple ecosystem services simultaneously. The area of the level 2 priority areas includes the level 1 priority areas

Perspectives on ES mapping and conservation priority setting methods

The effective mapping of ESs for conservation priority setting were very dependent on the availability of spatially explicit data and assessment approaches (Feng et al. 2010; Burkhard et al. 2012; Egoh et al. 2012; Martínez-Harms and Balvanera 2012; Crossman et al. 2013). In this study, the CASA model was used to map the spatial distribution patterns of NPP, the water balance equation was used to map the water supply and the USLE-based model was used to map soil conservation in the Jiangxi province (see the Methods section). These models served as the main tools for the spatial mapping of ESs and have been widely used at large spatial scales, such as the regional and national scale (Martínez-Harms and Balvanera 2012; Egoh et al. 2012; Crossman et al. 2013). Various researchers have used these models in their own scientific research on the Jiangxi province as a whole or in particular locations within the Jiangxi province, and all these models functioned effectively ( $\mathrm{Lu}$ et al.
2011; Yu et al. 2011; Gu et al. 2013; Lu et al. 2013). At the regional scale, we localized the parameterization and validation of these models based on in situ monitoring and modeling analyses so as to ensure the reliability of the mapping of ESs in the Jiangxi province for subsequent conservation efficiency analyses involving multiple ESs.

There have been numerous practical applications of the GIS-based OWA multi-criterion valuation methods in the identification of priority areas (Jiang and Eastman 2000; Malczewski et al. 2003; Malczewski and Rinner 2005; Robinson et al. 2010; Ricardo et al. 2013; Amiri et al. 2013), but few practical applications have been found in the identification of priority areas for conserving multiple ESs. Liu et al. (2013) discussed the use of OWA evaluation methods in the identification of priority areas for conserving ESs. Although our research also addresses the topic of ES priority setting, the analytical approaches of the two studies differ markedly. Liu et al. (2013) focused on analyzing the variations in conservation efficiency based on 
the two targets of conserving fixed total values of the ESs, and the variations in conservation efficiency, which can induce variability in the size of the selected priority areas. In contrast, our research focused on analyzing variations in conservation effectiveness based on the conservation of the top ES values in two fixed area targets. Because the spatial efficiency of the identified priority areas increases with the reduction in the size of the area, which would be quite small to promote conservation efficiency, threshold values of the conservation efficiency index or the total values of ESs for conservation are difficult to define, which may be confusing to decision-makers and stakeholders. Moreover, the greater the number of types of ESs selected for conservation, the less areas of intersection that these ESs will have. Therefore, using an arbitrary threshold value, based on expert knowledge, conservation efficiency and total values of ESs, it is quite difficult to assess the required size of the conservation areas, which is a major concern of decision-makers (Margules and Pressey 2000; Wilson et al. 2009; Chan et al.2011; Luck et al. 2012). The ideas presented in this paper can address this deficiency and help decision-makers by offering them a direct means of determining the appropriate area of ESs prioritized for conservation in target scenarios and of finding a balance between conservation efficiency, conservation costs, and the benefits of conservation planning.

\section{Conclusion}

The limited resources available for conservation of ESs call for prioritization schemes. The GIS-based OWA multi-criterion valuation methods provide decision-makers with an effective means by which to assess the risk and tradeoff levels of each potential policy scenario for balancing the conservation of multiple ESs simultaneously. In this paper, the spatial efficiency, risk, and tradeoff indices were used to measure the characteristics of each identified priority area of the various OWA scenarios developed. The main findings are as follows: (1) focusing on conserving an individual ES can only result in the highest spatial efficiency of the individual ES, and may induce the unwanted decline of other ESs, particularly when spatial trade-offs exist between them; (2) when conserving multiple ESs simultaneously, the use of GIS-based OWA methods can balance conflicts among multiple ESs and can significantly enhance the spatial efficiency of the identified priority areas overall. Decision-makers may integrate the spatial efficiency, risk and trade-off levels of each established OWA scenario with other specific conservation demands to achieve the goals set for the particular priority area chosen in the expectation of contributing to the effective conservation of multiple ESs simultaneously. This course of action may enhance the effectiveness of conservation by strategically considering conflicts and synergies among various ecosystem services.

Acknowledgments This work was funded by the National Natural Sciences Foundation of China (No. 41230745) and the National Environmental Conservation Research Program (201209027-4).

\section{References}

Amiri MJ, Mahiny AS, Hosseini SM, Jalali SG, Ezadkhasty Z, Karami S (2013) OWA analysis for ecological capability assessment in watersheds. Int J Environ Res 7(1):241-254

Balvanera P, Daily GC, Ehrlich PR, Ricketts TH, Bailey SA, Kark S, Kremen C, Pereira H (2001) Conserving biodiversity and ecosystem services. Science 291:2047

Bennett EM, Peterson GD, Gordon LJ (2009) Understanding relationships among multiple ecosystem services. Ecol Lett 12:1394-1404

Brooks TM, Mittermeier RA, da Fonseca GA, Gerlach J, Hoffmann M, Lamoreux JF, Mittermeier CG, Pilgrim JD, Rodrigues AS (2006) Global biodiversity conservation priorities. Science 313(5783):58-61

Budyko MI (1974) Climate and life. Academic Press, San Diego

Burkhard B, Kroll F, Nedkov S, Müller F (2012) Mapping supply, demand and budgets of ecosystem services. Ecol Indic 21:17-20

Butchart SHM, Walpole M, Collen B, van Strien A, Scharlemann JPW, Almond REA, Baillie JEM, Bomhard B, Brown C, Bruno J, Carpenter KE, Carr GM, Chanson J, Chenery AM, Csirke J, Davidson NC, Dentener F, Foster M, Galli A, Galloway JN, Genovesi P, Gregory RD, Hockings M, Kapos V, Lamarque JF, Leverington F, Loh J, McGeoch MA, McRae L, Minasyan A, Morcillo MH, Oldfield TEE, Pauly D, Quader S, Revenga C, Sauer JR, Skolnik B, Spear D, Stanwell-Smith D, Stuart SN, Symes A, Tierney M, Tyrrell TD, Vié JC, Watson R (2010) Global biodiversity: indicators of recent declines. Science 328(5982):1164-1168

Butler JR, Wong GY, Metcalfe DJ, Honzák M, Pert PL, van Rao N, Griekend ME, Lawson T, Bruce C, Kroon FJ, Brodie JE (2011) An analysis of trade-offs between multiple ecosystem services and stakeholders linked to land use and 
water quality management in the Great Barrier Reef. Agric, Ecosyst Environ, Australia

Carreño L, Frank FC, Viglizzo EF (2012) Tradeoffs between economic and ecosystem services in Argentina during 50 years of land-use change. Agric Ecosyst Environ 154:68-77

Chan KM, Hoshizaki L, Klinkenberg B (2011) Ecosystem services in conservation planning: targeted benefits vs. cobenefits or costs? PLoS ONE 6(9):e24378

Crossman ND, Burkhard B, Nedkov S, Willemen L, Petz K, Palomo I, Drakou EG, Martín-Lopez B, McPhearson T, Boyanovac K, Alkemade R, Egoh B, Dunbar MB, Maes J (2013) A blueprint for mapping and modelling ecosystem services. Ecosyst Serv 4:4-14

Daily GC (1997) Nature's services: societal dependence on natural ecosystem services, 1 st edn. Island Press, Washington

DeFiniens I (2004) eCognition. Software. http://www. definiensimaging.com. Accessed 17 Dec 2013

Ding QF, Wang JB, Qi SH, Ye H, Huang M, Xu YT, Ying TY, Tao J (2013) Spatial patterns of vegetation net primary productivity in Jiangxi Province of China in relation to climate factors. Chin J Ecol 32(3):726-732 (In Chinese)

Egoh B, Rouget M, Reyers B, Knight AT, Cowling RM, van Jaarsveld AS, Welz A (2007) Integrating ecosystem services into conservation assessments: a review. Ecol Econ 63(4):714-721

Egoh B, Drakou EG, Dunbar MB, Maes J, Willemen L (2012) Indicators for mapping ecosystem services: a review. Report EUR, 25456

Feng X, Fu B, Yang X, Lü Y (2010) Remote sensing of ecosystem services: an opportunity for spatially explicit assessment. Chin Geogr Sci 20(6):522-535

Fischer G, Nachtergaele F, Prieler S, van Velthuizen HT, Verelst L, Wiberg D (2008) Global agro-ecological zones assessment for agriculture (GAEZ 2008). IIASA, FAO, Laxenburg

Fisher B, Bradbury RB, Andrews JE, Ausden M, BenthamGreen S, White SM, Gill JA (2011) Impacts of species-led conservation on ecosystem services of wetlands: understanding co-benefits and trade offs. Biodivers Conserv 20(11):2461-2481

Goldman RL, Tallis H (2009) A critical analysis of ecosystem services as a tool in conservation projects. Ann N Y Acad Sci 1162(1):63-78

Gu J, Li X, Huang C, Zhang X, Jin X (2013) Simulating net primary productivity of Chinese terrestrial vegetation during 2000-2010. J Lanzhou Univ (Nat Sci) 49(2): 203-213 (In Chinese)

Haase D, Schwarz N, Strohbach M, Kroll F, Seppelt R (2012) Synergies, trade-offs, and losses of ecosystem services in urban regions: an integrated multiscale framework applied to the Leipzig-Halle region Germany. Ecol Soc 17(3):22

Hamon WR (1963) Computation of direct runoff amounts from storm rainfall. Int Assoc Sci Hydrol Pub 63:52-62

He Y, Che T, Wang Y (2012) Ecological footprint and endogenous economic growth in the Poyang Lake area in China based on empirical analysis of panel data model. J Resour Ecol 3(4):367-372

Hussain AM, Tschirhart J (2013) Economic/ecological tradeoffs among ecosystem services and biodiversity conservation. Ecol Econ 93:116-127
Izquierdo AE, Clark ML (2012) Spatial analysis of conservation priorities based on ecosystem services in the Atlantic forest region of misiones, Argentina. Forests 3(3):764-786

Jax K, Barton DN, Chan K, de Groot R, Doyle U, Eser U, Görg C, Gómez-Baggethun E, Griewald Y, Haber W, HainesYoung R, Heink U, Jahn T, Joosten H, Kerschbaumer L, Korn H, Luck GW, Matzdorf B, Muraca B, Neßhöver C, Norton B, Ott K, Potschin M, Rauschmayer F, von Haaren C, Wichmann S (2013) Ecosystem services and ethics. Ecol Econ 93:260-268

Jiang H, Eastman JR (2000) Application of fuzzy measures in multi-criteria evaluation in GIS. Int J Geogr Inform Syst 14:173-184

Lautenbach S, Volk M, Gruber B, Dormann CF, Strauch M, Seppelt R (2010) Quantifying ecosystem service tradeoffs. In: International Environmental Modelling and Software Society (iEMSs). 2010 International Congress on Environmental Modelling and Software Modelling for Environment's Sake. Ottawa, Canada

Li X, Zhuge H, Mengdi L (2013) Gap analysis and conservation network for freshwater wetlands in Central Yangtze Ecoregion. Sci World J. doi:10.1155/2013/918718

Liu Y, Zhang H, Yang X, Wang Y, Wang X (2013) Identifying priority areas for the conservation of ecosystem services using GIS-based multicriteria evaluation. Pol J Ecol 61(1):415-430

Lu J, Sun G, McNulty SG, Amatya DM (2005) A comparison of six potential evapotranspiration methods for regional use in the southeastern United States1. JAWRA J Am Water Resour Assoc 41(3):621-633

Lu J, Chen X, Li H, Liu H, Xiao J, Yin J (2011) Soil erosion changes based on GIS/RS and USLE in Poyang Lake basin. Trans CSAE 27(2):337-344 (In Chinese)

Lu N, Sun G, Feng X, Fu B (2013) Water supply responses to climate change and variability across the North-South Transect of Eastern China (NSTEC). J Hydrol 481: 96-105

Luck GW, Chan KM, Klien CJ (2012) Identifying spatial priorities for protecting ecosystem services. F1000 Res 1:17

MA (Millennium Ecosystem Assessment) (2005) Ecosystems and human well-being: synthesis. Island Press, Washington

Mace GM, Norris K, Fitter AH (2012) Biodiversity and ecosystem services: a multilayered relationship. Trends Ecol Evol 27(1):19-26

Maes J, Paracchini ML, Zulian G, Dunbar MB, Alkemade R (2012) Synergies and trade-offs between ecosystem service supply, biodiversity, and habitat conservation status in Europe. Biol Conserv 155:1-12

Malczewski J, Chapman T, Flegel C, Walters D, Shrubsole D, Healy MA (2003) GIS-multicriteria evaluation with ordered weighted averaging (OWA): case study of developing watershed management strategies. Environ Plan A 35(10):1769-1784

Malczewski J, Rinner C (2005) Exploring multicriteria decision strategies in GIS with linguistic quantifiers: a case study of residential quality evaluation. J Geogr Syst 7(2):249-268

Margules CR, Pressey RL (2000) Systematic conservation planning. Nature 405(6783):243-253

Martínez-Harms MJ, Balvanera P (2012) Methods for mapping ecosystem service supply: a review. Int J Biodivers Sci, Ecosyst Serv Manag 8(1-2):17-25 
Moilanen A Meller L, Leppänen J, Pouzols MF, Arponen A, Kujala H (2013) Spatial conservation planning framework and software ZONATION Version 3.1 User manual. Biodiversity Conservation Informatics Group Department of Biosciences University of Helsinki, Finland, p 288

Nelson E, Mendoza G, Regetz J, Polasky S, Tallis H, Cameron D, Chan KM, Daily GC, Goldstein J, Kareiva PM, Lonsdorf E, Naidoo R, Ricketts TH, Shaw M (2009) Modeling multiple ecosystem services, biodiversity conservation, commodity production, and tradeoffs at landscape scales. Front Ecol Environ 7(1):4-11

Paviolo A, di Blanco YE, de Angelo CD, di Bitetti MS (2009) Protection affects the abundance and activity patterns of pumas in the Atlantic Forest. J Mammal 90:926-934

Pimm SL, Russell GJ, Gittleman JL, Brooks TM (1995) The future of biodiversity. Science 269(5222):347-350

Pimm SL, Jenkins CN, Abell R, Brooks TM, Gittleman JL, Joppa LN, Raven PH, Robert CM, Sexton JO (2014) The biodiversity of species and their rates of extinction, distribution, and protection. Science 344(6187): 1246752

Polasky S, Johnson K, Keeler B, Kovacs K, Nelson E, Pennington D, Plantinga AJ, Withey J (2012) Are investments to promote biodiversity conservation and ecosystem services aligned? Oxf Rev Econ Policy 28(1):139-163

Potter CS, Randerson JT, Field CB, Matson PA, Vitousek PM, Mooney HS, Klosster SA (1993) Terrestrial ecosystem production: a process model based on global satellite and surface data. Glob Biogeochem Cy 7:811-841

Ricardo DT, Ershun Z, Yang ZH, Arisleydis P (2013) A local spatial decision support system for developing countries based on MCA, fuzzy sets and OWA - case study of a municipality in Cuba. Geo-spatial Inf Sci 16(2):120-129

Rodrigues ASL (2006) Are global conservation efforts successful? Science 313(5790):1051-1052

Sharpley AN, Williams JR (1990). EPIC-erosion/productivity impact calculator: 1. Model documentation. Technical Bulletin-United States Department of Agriculture, (1768 Pt 1)

Singh SP (2002) Balancing the approaches of environmental conservation by considering ecosystem services as well as biodiversity. Curr Sci 82:1331-1335

Robinson TP, van Klinken RD, Metternicht G (2010) Comparison of alternative strategies for invasive species distribution modeling. Ecol Model 221(19):2261-2269
Rodríguez JP, Beard TD, Bennett EM, Cumming GS, Cork SJ, Agard J, Dobson AP, Peterson GD (2006) Trade-offs across space, time, and ecosystem services. Ecol Soc 11(1):28

Tallis H, Goldman R, Uhl M, Brosi B (2009) Integrating conservation and development in the field: implementing ecosystem service projects. Front Ecol Environ 7(1):12-20

Turner WR, Brandon K, Brooks TM, Costanza R, Da Fonseca GA, Portela R (2007) Global conservation of biodiversity and ecosystem services. Bioscience 57(10):868-873

Wang J, Lü Y, Zeng Y, Zhao Z, Zhang L, Fu B (2014) Spatial heterogeneous response of land use and landscape functions to ecological restoration: the case of the Chinese loess hilly region. Environ Earth Sci. doi:10.1007/s12665-0143175-z

Wilcove DS, Rothstein D, Dubow J, Phillips A, Losos E (1998) Quantifying threats to imperiled species in the United States. Bioscience 48(8):607-615

Wilcove DS (2008) No way home: the decline of the world's great animal migrations. Island Press, Washington

Wilson KA, Cabeza M, Klein CJ (2009) Fundamental concepts of spatial conservation prioritization. Spatial Conservation Prioritisation: Quantitative Methods and Computational Tools. Oxford University Press, New York

Wischmeier WH, Smith DD (1965) Predicting rainfall-erosion losses from cropland east of the rocky mountains-guide for selection of practices for soil and water conservation. US Department of Agriculture, Washington

Wischmeier WH, Smith DD (1978) Predicting rainfall erosion losses: a guide to conservation planning. Agriculture handbook, vol 537. US Department of Agriculture (USDA), Washington, pp 5-8

Yager RR (1988) On ordered weighted averaging aggregation operators in multi-criteria decision making. IEEE Trans Syst Man Cybernet 18(1):183-190

Yu J, Zheng B, Liu Y, Liu C (2011) Evaluation of soil loss and transportation load of adsorption $\mathrm{N}$ and $\mathrm{P}$ in Poyang Lake watershed. Acta Ecologica Sinica 31(14):3980-3989 (In Chinese)

Zhang L, Dawes WR, Walker GR (2001) Response of mean annual evapotranspiration to vegetation changes at catchment scale. Water Resour Res 37(3):701-708

Zhou Q, Liu X (2006) Digital topography analysis. Science Press, Beijing, pp 79-132 (In Chinese) 